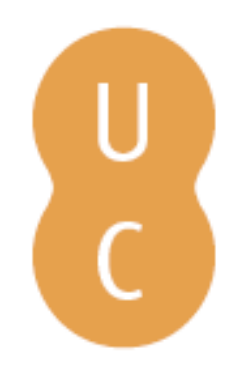

\title{
pommalina
}

\section{As dinâmicas europeias, entre os Estados, as redes e os atores multiterritoriais}

\author{
Autor(es): $\quad$ Fernandes, João Luís J.
}

Publicado por: Imprensa da Universidade de Coimbra

URL

persistente: URI:http://hdl.handle.net/10316.2/47296

DOI: $\quad$ DOl:https://doi.org/10.14195/978-989-26-1849-4_5

Accessed : $\quad$ 26-Apr-2023 12:25:38

A navegação consulta e descarregamento dos títulos inseridos nas Bibliotecas Digitais UC Digitalis, UC Pombalina e UC Impactum, pressupõem a aceitação plena e sem reservas dos Termos e Condições de Uso destas Bibliotecas Digitais, disponíveis em https://digitalis.uc.pt/pt-pt/termos.

Conforme exposto nos referidos Termos e Condições de Uso, o descarregamento de títulos de acesso restrito requer uma licença válida de autorização devendo o utilizador aceder ao(s) documento(s) a partir de um endereço de IP da instituição detentora da supramencionada licença.

Ao utilizador é apenas permitido o descarregamento para uso pessoal, pelo que o emprego do(s) título(s) descarregado(s) para outro fim, designadamente comercial, carece de autorização do respetivo autor ou editor da obra.

Na medida em que todas as obras da UC Digitalis se encontram protegidas pelo Código do Direito de Autor e Direitos Conexos e demais legislação aplicável, toda a cópia, parcial ou total, deste documento, nos casos em que é legalmente admitida, deverá conter ou fazer-se acompanhar por este aviso.

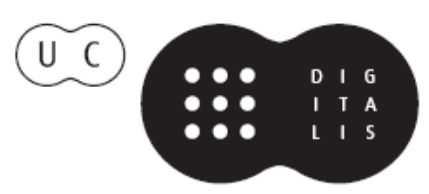


Euro-Atlântico:

Espaço de Diálogos

Isabel Maria Freitas Valente

Iranilson Buriti de Oliveira

(Coord)

\section{VISÕES \\ INTERDISCIPLINARES \\ DA EUROPA \\ E DO MUNDO:}

uma experiência de convergência

disciplinar em homenagem a

Maria Manuela Tavares Ribeiro

Alexandra Aragão

Isabel Maria Freitas Valente

Dulce Lopes

(org.)

Editora da Universidade Federal de Campina Grande

Imprensa da Universidade de Coimbra

2019 


\title{
AS DINÂMICAS EUROPEIAS, ENTRE OS ESTADOS, AS REDES E OS ATORES MULTITERRITORIAIS
}

João Luís J. Fernandes, PhD

FLUC/CEIS20

E-mail: geo.jesus.fernandes@gmail.com

"À medida que avançamos no século XXI, em tempos de mundialização, impõe-se questionar criticamente a Europa, velho continente, hoje novo mundo a redescobrir na sua modernidade - efeito de uma convergência histórica e de uma nova geografia que continua a fazer-se. Interacção entre o espaço, o político, o social, o cultural, o religioso - questão esta, complexa e multifacetada - hoje, e no futuro, reactivada. Quais serão as fronteiras finais da Europa?"

Maria Manuela Tavares Ribeiro (2004, p.10).

\section{Resumo}

Este artigo parte de uma análise crítica das representações cartográficas "não realistas" e "tendenciosas" da Europa, para suscitar uma série de questões sobre os fenómenos de multiterritorialização de diferentes tipos de actores e seus poderes.

Palavras-chave: Europa; Multiterritorialização; Geografia.

\begin{abstract}
This article starts with a critical analysis of the "unrealistic" and "biased" cartographic representations of Europe, to raise a series of questions about the phenomena of multiterritorialisation of different types of actors and their powers.
\end{abstract}

Keywords: Europe; Multiterritorialisation; Geography.

A perceção visual que se tem da Europa resulta, em parte, da representação cartográfica dominante que se estuda nas escolas e se divulga em múltiplas plataformas analógicas e digitais. Num dos mais 
conhecidos planisférios, o território europeu tem limites indefinidos a leste e termina, no setor ocidental, nas costas que confinam com o Atlântico. Nesta mesma imagem, a Europa está posicionada no centro, dando uma aparente relevância a países como Portugal (Figura 1).

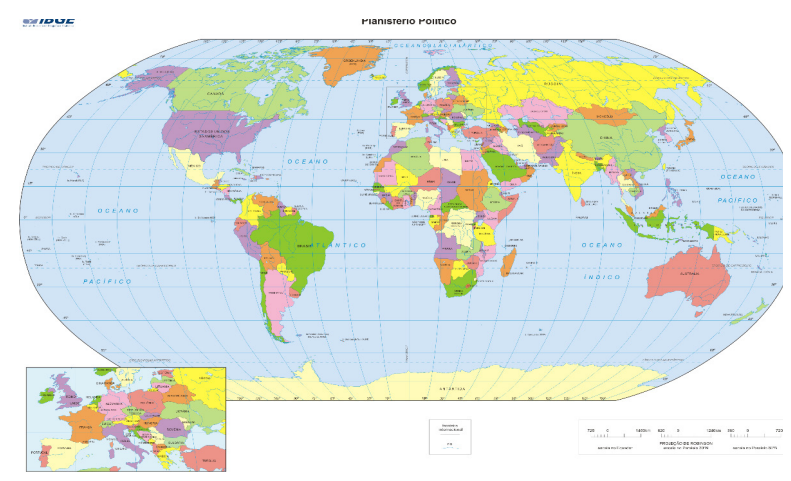

Figura 1 - Planisfério político, com destaque, numa escala maior, para a representação da Europa. Fonte: IBGE, editado por http://www.baixarmapas.com.br

Nesta representação mais comum, o espaço continental europeu encontra-se fragmentado por um rendilhado de mosaicos com áreas bem delimitadas, quase sempre ilustradas e diferenciadas por diversas cores. Daqui resulta um padrão policromático e um emaranhado de unidades heterogéneas, com diferentes formas e dimensões variadas. Esta é a Europa dos Estados, entidades bem delimitadas e identificadas, sobretudo se se observarem a outra escala, numa qualquer caixa que amplie o espaço e facilite a observação, como se pode também verificar na figura 1 , no caso do continente europeu.

Esta imagem não retrata a realidade. Pelo contrário, como ocorre com todos os mapas, esta é uma representação parcial e tendenciosa do objeto. Desde logo, pelo eurocentrismo desta cartografia. Depois, porque as projeções utilizadas distorcem a verdadeira dimensão e forma dos espaços geográficos. A projeção mais comum, a de Mercator, amplia a Europa e territórios como a Gronelândia. Nesta visão eurocentrada do mundo, o hemisfério sul, em particular o continente africano, são reduzidos relativamente à sua extensão real. 
Estes mapas, que também mentem (Monmonier, 1996), estão condicionados por outro enviesamento de perceção. A Europa representada tem a aparência de um território estático que se prolonga no tempo. Pelo que se visualiza, este é um mundo parado e imutável.

Esta inércia pode ser compensada pela apresentação sequenciada de múltiplos mapas organizados num friso temporal. Ao longo do tempo, as linhas que ilustram as fronteiras podem alterar-se, as células que definem os Estados vão ganhando outras dimensões e novos contornos, a paleta colorida vai-se modificando. Assim acontece, é apenas um exemplo, no Atlas da Europa (Vários autores, 1992), publicado com o sugestivo subtítulo A Geografia da Europa Através dos Tempos. Afinal, esta realidade estática torna-se anacrónica e renova-se. Ao mesmo tempo, esta palete policromada tem alguma plasticidade e ajusta-se a novos contextos.

Ainda assim, se nos detivermos perante um mapa isolado, ainda que desatualizado, fica-nos a ideia do tempo longo da permanência, de uma geografia pouco flexível, mais estática que dinâmica. Nesta representação de uma Europa de países e Estados, por vezes acrescentamse setas que sugerem fluxos variados, como as mobilidades espaciais das populações ou qualquer outra deslocação material e material entre dois pontos georreferenciados separados por alguma distância. No entanto, a inércia, a Europa estática e a ausência de movimento são aqui dominantes.

Todos estes desvios - a centralidade da Europa, as dimensões adulteradas, a imobilidade que parece sugerir que o mundo não muda e que as assimetrias se manterão nos mesmos moldes e com a mesma arquitetura espacial, podem ser vistas como manifestações de poder.

Para Mark Monmonier (2010, p.1), "maps exert power (...) by shaping public opinion". Este mesmo autor (2010, p.xii), refere-se ao mapa como " (...) a powerful tool of persuasion". Significa isto que as representações condicionam as perceções, as mundividências e os mapas mentais que, no limite, se podem traduzir em comportamentos.

Ainda regressando ao planisfério e ao mapa da Europa ilustrado na figura 1, sob o ponto de vista geográfico este é o domínio das 
métricas euclidianas, das distâncias medidas por quilómetros e de um espaço contínuo ordenado por linhas (como as fronteiras políticas e os contornos do litoral, por exemplo) e áreas (os Estados, cada um com uma forma específica).

Este mapa poderá induzir outra questão: os protagonistas deste continente são os Estados, aqui ajustados ao conceito de país, com os seus limites e as suas áreas de soberania. Contudo, num exercício fundamental em Geografia, é necessário alterar o ângulo de observação e mudar as escalas geográficas de análise. Neste mapa estatal, escondem-se outros limites e outras demarcações espaciais. Ainda numa lógica de espaço contínuo, o cartógrafo pode apurar o olhar e descobrir, no exemplo português, regiões, municípios ou freguesias. Ainda em Portugal, a territorialidade administrativa de outras instituições acrescenta novos rendilhados. As áreas turísticas, as demarcações judiciais, as regiões agrárias, entre outras, contribuem para a sobreposição de espaços contínuos, cada um com as suas delimitações, formas e áreas de influência.

Noutros países, as denominações serão diferentes, mas a lógica mantém-se. Para recolha e organização de dados, para comparar territórios mas também para a preparação e monitorização de políticas públicas, desenharam-se novas unidades na Europa, a Nomenclatura das Unidades Territoriais para Fins Estatísticos, organizadas em diferentes escalas e níveis espaciais: as NUT I, NUT II e NUT III.

Mesmo quando se cartografam outros espaços, como o marítimo, predomina a lógica das espacialidades contínuas. As Zonas Económicas Exclusivas (ZEE), as delimitações da Plataforma Continental ou as Search and Recue Areas (SRA), são disso exemplo.

Com a integração europeia e a agregação do país a entidades como a NATO, criam-se unidades supranacionais, mas a lógica do espaço contínuo persiste, ainda que se introduzam aqui descontinuidades geográficas associadas, por exemplo, às regiões insulares.

Ainda noutra escala geográfica e com propósitos diferentes, a mesma representação cartográfica é aplicada às áreas culturais que, segundo Samuel Huntington (1999), dividiriam o mundo em células civilizacionais 
caraterizadas pela homogeneidade interna e pelo contraste em relação ao exterior. Estas unidades formariam um rendilhado contínuo de mosaicos que poderiam entrar em conflito, daqui resultando um choque de civilizações.

Esta realidade espacial tem o mérito de assumir o dinamismo. No entanto, incorre noutras imprecisões. Nesta representação de Huntington (1999), as unidades civilizacionais são espaços uniformes, sem os contrastes internos que apenas se evidenciariam observando essa realidade a partir de escalas geográficas de maior pormenor. Para além disso, a esta leitura superficial e panorâmica de realidades complexas, faltam considerar os fluxos e as redes, que envolvem atores que, seguindo outras métricas, têm uma organização territorial mais flexível e não exclusivamente areal.

Como se lê em autores como Niall Ferguson (2017), a organização em rede de instituições e atores muito variados não é uma novidade histórica. Esta estruturação mais horizontal, flexível, difusa, multilateral e dinâmica de determinados protagonistas, há muito que se confronta com as estruturas rígidas, verticalizadas e disciplinares de atores como os atuais Estados, que se expressam territorialmente por soberanias areais e por territorialidades de espaços contínuos e em mosaico.

Este autor (Ferguson, 2017) recorre à metáfora da torre (que simbolizaria as relações horizontais), e da praça (o espaço das relações flexíveis e horizontais). Entender a Europa implica ampliar o olhar e abrir a objetiva para estes dois mundos. O primeiro mais estável, o segundo mais fluído e inconstante.

Para autores como Manuel Castells (1997), João Ferrão (2003) ou Rogério Haesbaert (2004), a realidade geográfica das redes coexiste com a rigidez espacial dos espaços contínuos, também denominados patrimoniais. Estas territorialidades euclidianas clássicas convivem e associam-se a outras métricas geográficas - a dos fluxos e as das relações topológicas em redes, nas quais, à posição geográfica tradicional, se deve acrescentar o valor das ligações e das conetividades (Figura 2). 


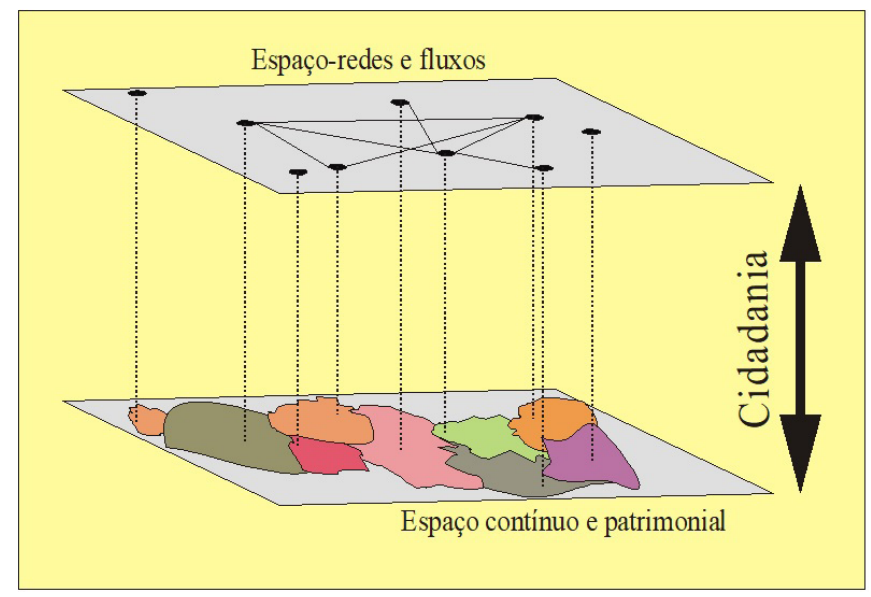

Figura 2 - A cidadania enquanto associação dos espaços contínuos e dos espaços redes e fluxos.

Por além disso, a aceleração dos movimentos e das mobilidades, a compressão espaço-tempo e o desenvolvimento técnico, em especial no que à informática e ao ciberespaço diz respeito, foram alimentando determinismos tecnológicos que, no limite, consideraram o mundo como uma realidade plana na qual as velhas questões geográficas (a localização, as acessibilidades e as distâncias) perderiam sentido e deixariam de ser diferenciadoras (Harvey, 2002; Friedman, 2005).

Este excesso de otimismo a respeito do poder das novas tecnologias de informação, determinantes em área como os mercados financeiros, conduziu ao anúncio da morte e do fim da Geografia enquanto ciência dedicada ao estudo das rugosidades do espaço e do seu efeito de atrito na dinâmica dos fenómenos económicos, sociais, políticos ou culturais (O’Brien, 1992).

Perante disso, somos confrontados com dois discursos e duas abordagens extremas a respeito do espaço geográfico, dos territórios e das territorialidades.

a) Por um lado, consideram-se os territórios organizados enquanto 
células contínuas, bem delimitadas em relação ao exterior. Aqui, tanto podemos incluir a organização espacial do Estado e dos países representados no mapa que deu início a este texto, como podemos considerar as geografias que resultam dos desdobramentos espaciais das entidades estatais, quer em escalas supranacionais, quer em escalas subnacionais. Nesta dimensão de espaço contínuo, incluem-se também as grandes áreas civilizacionais, de Samuel Huntington. Para Rogério Haesbaert (2004), estamos aqui no domínio dos territórios-zona.

b) Por outro, temos os discursos e as representações em torno dos denominados, por Rogério Haesbaert (2004), territórios-rede, isto é, espacialidades mais flexíveis associadas à velocidade, à descontinuidade geográfica e a métricas topológicas, que valorizam mais a conetividade que a localização espacial identificada por georreferenciações absolutas.

Estas duas perspetivas apenas são aqui divididas para facultar uma discussão académica mais clara. Na verdade, encontram-se interligadas, pois ambas são fundamentais e imprecindíveis para entender a contemporaneidade em territórios como a Europa.

Como se discute em Tim Marshall (2017), a atualidade continua marcada, e prisioneira (fazendo-se aqui alusão ao título da obraprisioneiros da Geografia) das velhas questões geográficas. Entre estas encontram-se as fronteiras políticas e os espaços contínuos de soberania, mas também a localização, o acesso ao mar, a continentalidade ou a insularidade, o maior ou menor encravamento dos espaços nacionais, o clima, os solos mais ou menos férteis ou, entre outros aspetos, a orografia. Marshall (2017) enfatiza, no caso do continente europeu, a Europa meridional, condicionada pela menor densidade de solos férteis, pelo relevo acidentado, pelas penínsulas (a Península Ibérica, a Itália ou a Grécia) e pela maior dificuldade histórica de comunicação e circulação de pessoas e mercadorias. Em contraste, mais a norte, a Europa abre-se ao movimento através da grande planície que se estende da região setentrional de França em direção ao centro da Eurásia, algures na fronteira dos Urais, passando por países como a Alemanha e 
a Rússia e, entre estes, a Polónia, daqui resultando a centralidade (mas também a instabilidade) geopolítica do território polaco.

Por outro, em espaços geográficos como a Europa, e não só (porque esta é uma questão global), movimentam-se atores que, com um peso elevado na geografia do poder mas não escapando à lógica dos espaços contínuos, também se organizam em redes. Incluem-se aqui, por exemplo, entidades bancárias e financeiras; bolsas de valores e companhias de seguros; empresas multinacionais, que têm na Europa muitos dos seus nós; mas também universidades ou, noutro contexto, tribos urbanas, comunidades em muito estruturadas pelas redes sociais.

Nesta contemporaneidade complexa e híbrida, sem que se oponham, tanto importam as questões que derivam do solo (analógico) que pisamos, como aquelas relacionadas com o movimento, os fluxos, as trocas e o ciberespaço, com todas as potencialidades e riscos que daqui derivam.

Para Haesbaert (2002 e 2004) e Ferrão (2003), a cidadania cumprese pela conjugação destes dois níveis espaciais. O cidadão continua a orientar-se pelo seu passaporte e pelo cartão de cidadão (que o filia a uma territorialidade areal), mas também pela sua integração em redes (hoje em muito associada às redes sociais, por exemplo), que o associa às métricas topológicas dos fluxos e dos espaços reticulares.

Para estes autores, é na conjugação destes dois mundos geográficos que se alcança a denominada multiterritorialidade, isto é, a interrelação permanente e integrada de cada um dos cidadãos com estes dois mundos geográficos. Esta multiterritorialidade não é um dado universal. Cada cidadão, cada ator, cada instituição, tem uma multiterritorialidade diferente. A multiterritorialidade é um capital desigualmente distribuído.

No limite, como refere Haesbaert (2002), alguns usufruem de uma multiterritorialidade mais elástica e expansiva, enquanto outros vivem confinados em territorialidades de curta distância. Por exemplo, no primeiro caso podemos citar uma elite infoincluída que, sem perder as suas referencias espaciais clássicas, se desloca com facilidade pelo mundo e interage com atores e instituições geograficamente distantes.

No entanto, como se pode acompanhar pelas discussões deste 
geógrafo brasileiro (Haesbaert, 2002 e 2004), é também possível identificar faixas da população que não usufruem desta mesma multiterritorialidade e revelam práticas de inércia e encravamento espacial. Como refere Haesbaert (2002, p. 45), “(...) coexistem hoje diversas formas de experimentar "integralmente" o espaço. Se convivemos num mundo tão desigual e com uma massa tão grande de excluídos, é evidente que vamos encontrar desde a elite que efetivamente usufrui da multiterritorialidade e da multi-escalaridade planetária, até os grupos mais fixados à terra, como os indígenas e os pequenos agricultores, e aqueles quase totalmente dela excluídos, como muitos dos sem-teto defendendo suas marquises ou seus abrigos em viadutos nas ruas das grandes cidades".

Nesta geometria variável, sobretudo no que respeita ao papel das redes na Europa e na perturbação do aparentemente tranquilo mapa político do continente europeu referido no início deste texto, centremonos na análise introdutória das redes migratórias - as diásporas, sem as quais a geografia da Europa não se pode compreender.

Fazendo parte das ethnoscapes em movimento no contexto global contemporâneo (Appadurai, 2004), as redes migratórias organizamse em estruturas que, a partir de um ponto de difusão espacial, se distribuem por diferentes vértices. Nesta organização em estrela, o lugar de partida é um território de divergência de uma população migrante unida pela nacionalidade mas também por laços de natureza cultural e identitária, como a língua, a religião ou a filiação étnica. Esta saída implica uma reconfiguração espacial, uma desorientação geográfica em resultado do afastamento em relação aos territórios do quotidiano. Aplicando ainda os termos de Rogério Haesbaert (2004), estas mudanças de contexto podem configurar um processo de desterritorialização. É nos lugares de chegada, nos vértices geograficamente dispersos e descontínuos, que se processa uma reorientação espacial do migrante e uma reconfiguração dos seus mapas pessoais, que podemos denominar como reterritorialização.

Essa pode ocorrer de diversos modos, pode ser mais completa ou incompleta, pode realizar-se com maior ou menor abertura em relação 
aos lugares de chegada. No geral, nessa reterritorialização mobiliza-se a memória e promove-se o efeito de grupo e de comunidade. Em muitos casos, nestas geografias mais longínquas mas de afetividade e topofilia em relação ao ponto de partida, faz-se a encenação (material e imaterial) dos territórios de origem. Significa isso que esta rede identitária é um território difuso de circulação de pessoas, mercadorias e bens materiais, mas também de valores e crenças, línguas, religiões e diferentes formas de capital. Nestas redes que se afirmam como um poder que pode escapar à regulação tradicional dos Estados, a circulação acontece em múltiplos sentidos e direções: do centro para os vértices, mas também dos vértices para o centro (veja-se, por exemplo, o papel das remessas da emigração em múltiplos casos). Noutros, os fluxos ocorrem entre os próprios vértices (não sendo difícil identificar exemplos, como a relação que se estabelece entre as comunidades de imigrantes islâmicos distribuídas por diferentes cidades europeias).

Nesse sentido, é importante considerar a Europa, no seu todo mas também nas suas microespacialidades, como um ponto difusor de múltiplas diásporas. Por isso é possível reconhecer uma Europa fora do continente europeu. Por essa razão se pode viajar por paisagens que encenam a cultura europeia em contextos geográficos distantes e pouco familiares.

São muitos os exemplos, mas detenhamo-nos no Estado de Santa Catarina, no Brasil. Ali se promove, na cidade de Blumenau, a cultura germânica, a arquitetura em enxaimel ou a Oktoberfest. Nestas anatopias, isto é, nesta deslocalização de elementos geográficos e culturais para contextos afastados e distintos dos originais, o discurso é sobretudo tradicionalista e conservador. O passado é aqui um refúgio que une a comunidade no seu processo de reterritorialização.

O mesmo ocorre noutras cidades da região. Em Treze Tílias, outro exemplo, promove-se uma filiação austríaca, encenando um território alpino localizado no hemisfério sul. Na serra gaúcha, a encenação europeia está representada nas paisagens vinícolas, de inspiração italiana, o mesmo ocorrendo com múltiplos exemplos da colonização portuguesa, de Ouro Preto a São Salvador da Baía. 
Contudo, estes canais ultrapassam o aspeto geossímbólico. A diáspora irlandesa é disso exemplo. A celebração do St. Patrick deu importância a Nova Iorque. Nesse dia, aquele é o centro da diáspora irlandesa. No entanto, foi também a partir dos EUA que, em parte, se promoveu a independência da República da Irlanda,ocorrida em 1922 após a eclosão de uma série de conflitos, alguns ocorridos na própria Dublim.

Apesar da integração na União Europeia, foi também a mobilização dos elos que ligam o centro da diáspora irlandesa com o seu vértice norte americano que orientou a estratégia deste país nas últimas décadas. Como refere Breda Gray (2012), a diáspora assume-se, nessas circunstâncias, como um relevante poder paralelo ao Estado.

Olhando para a paisagem portuguesa e respetiva geografia humana, é impossível não observar os efeitos materiais e simbólicos dos fluxos que, a partir dos vértices, se territorializam no local de partida. Com efeito, o retorno do emigrante pode significar um novo processo de reterritorialização e, também neste caso, se promovem nossas encenações. Agora, no regresso, encena-se o Brasil, França ou os Alpes suíços. A arquitetura alógena pode ser também uma anatopia - uma casa com telhados alpinos numa qualquer aldeia beirã poderá ter esta leitura.

Com efeito, com todo este dinamismo geográfico, a Europa deve ser entendida enquanto lugar de origem e ponto difusor de múltiplas diásporas (da alemã à polaca, da irlandesa à italiana e à portuguesa e, dentro destas, noutra escala, da siciliana à calabresa, mas também da madeirense à açoriana, apenas para citar alguns exemplos).

No entanto, nesta Europa em movimento, neste continente europeu instável, líquido e sempre transitório, é preciso mudar a perspetiva. Esta Europa é também o vértice de múltiplas diásporas que aqui se procuram reterritorializar. Consoante o ponto de observação no vasto continente europeu, há a considerar a diáspora paquistanesa e indiana, mas também a marroquina e a argelina, a brasileira e, entre outras, a caboverdiana, cada uma com as suas dinâmicas e geografias, cada uma com o seu potencial de mobilização de fluxos materiais e imateriais, 
com os seus discursos identitários e de agregação.

O debate sobre a identidade europeia, as fronteiras culturais e a multiculturalidade, tudo se associa a esta dinâmica complexa e multivariada. Em tempos de crise, insegurança e incertezas, também se evocam os fluxos promovidos por estas estruturas migratórias transnacionais. Teme-se que, pelos canais que unem os centros e os vértices destas diásporas, possam circular ameaças e riscos. Com isso, a desconfiança e o medo instalam-se.

Esta associação ocorre por várias razões, mas também porque é em rede que se organizam os atores informais da criminalidade e do terrorismo, criando campos de contacto nos quais nem sempre é fácil a destrinça com as redes migratórias, em muitos casos apropriadas de forma abusiva por atores oportunistas.

Assim ocorreu com a exportação das redes mafiosas italianas para os EUA, em especial para cidades como Chicago. Como referem Mastrobuoni and Patacchini (2012, p.25) "that not only is the American Mafia an Italian enterprise, it values direct links with Sicilians more than with people from other parts of Italy. Sicilian kin-centered social system, with its code of honor and vow of silence, forms the building block for the Mafia."

Assim tem ocorrido com a apropriação de lugares de reterritorialização de imigrantes islâmicos na Europa (como Molenbeek, em Bruxelas) por parte de redes fundamentalistas religiosas que promovem discursos e práticas de violência.

Perante isto, a Europa dos Estados é confrontada com redes difusas de ilegalidade, informalidade e criminalidade, marcadas pela plasticidade e por uma cartografia mais incerta. Estes são atores multiterritoriais, pelo modo como tiram partido dos espaços contínuos mas também dos territórios-fluxo e das ligações topológicas (Haesbaert, 2002). Nestas geografias subterrâneas, promovem-se poderes, circulam estupefacientes, faz-se o tráfico de imigrantes clandestinos e deslocamse armas clandestinas.

Nestes fluxos, o controlo e a regulação contituem um desafio. Os limites estatais e as lógicas reguladoras dos espaços contínuos estão mal 
adaptados a estas geografias flexíveis e porosas, em muito alavancadas pelas potencialidades comunicativas do ciberespaço.

Este será sempre um confronto entre o mundo mais estável da regulação e as dinâmicas mais incertas e desreguladas dos fluxos. Esse choque foi evidente na crise dos refugiados que se seguiu ao verão de 2015, mas tem-se também traduzido nas arquiteturas incertas de poderes que não são nem fáceis de identificar nem de cartografar (Rothkopf, 2008).

Este balanço incerto e instável entre os espaços contínuos e os fluxos, entre os territórios de continuidade e os de descontinuidade geográfica, entre o que está próximo e o que está distante, deve estar no horizonte das estratégias prospetivas da União Europeia e de cada um dos seus Estados, como se pode acompanhar, no caso português, pelo Conceito Estratégico de Defesa Nacional (Governo de Portugal, 2013). Neste documento, enquanto fatores relevantes para o país, citam-se espaços geográficos como a Europa e o Atlântico, mas também as redes de emigração.

A desregulação do sistema perante instrumentos convencionais de controlo, a conjugação de espaços geográficos de métricas diferenciadas e a consequente multiterritorialidade dos atores, levantam questões e desafios políticos importantes para o futuro da Europa.

Desde logo, enquanto condição de flexibilidade e plasticidade, a multiterritorialidade é uma forma de poder que tanto poderá ser instrumentalizada para a promoção do risco e da insegurança, como pode ser convocada para movimentos de sentido contrário, de promoção dos valores da solidariedade, da partilha e da paz.

Esta multiterritorialidade pode também ser um fator de resistência perante poderes globais, como ocorreu em Berlim, com a movimentação em rede que se opôs à instalação de edifícios, equipamentos e serviços da Google no bairro de Kreuzberg (O'Sullivan, 2018).

Por outro lado, e continuamos nos desafios políticos, será importante acompanhar o desencontro que persiste entre o exercício da cidadania eleitoral, muito vinculada aos territórios-zona (por exemplo, no caso português, vota-se num país, num município, numa freguesia) e as 
identidades flexíveis e topoligâmicas. Esta tensão entre o cidadão multiterritorial de pertenças geográficas híbridas e compósitas e o mais inflexível cidadão eleitor, vinculado a espaços geográficos contínuos e confinados, poderá, ou não, ser um fator de perturbação do sistema, numa matéria a acompanhar não pelo geógrafo nem pela Geografia, mas sim pela ciência política.

Em suma, como referia Maria Manuela Tavares Ribeiro em 2010, no continente europeu persiste uma fratura entre a tradição e a modernidade. Para Tavares Ribeiro, esta cesura entre o antigo e o novo acompanha a própria Ideia de Europa.

Ainda para Manuela Tavares Ribeiro (2004, p.11), a Europa é um "mosaico rico, complexo, diversificado", concebido "em ideias várias, em ópticas diversas, com fronteiras feitas, desfeitas ou refeitas".

Neste devir de fronteiras oscilantes, os Estados verticalizados, hierarquizados e de soberania inscrita nos espaços contínuos, terão uma convivência difícil com os novos atores, mais fluídos e flexíveis. Para além disso, os Estados representados nos planisférios políticos correspondem a um momento na História da Europa. Estas entidades estatais estarão a meio caminho entre um passado que as ideologias nacionalistas simplificaram e reduziram, e um futuro que, perante as novas tecnologias e a emergência de atores com um poder multiterritorial acrescido, reduz a sua capacidade de regulação mas também o seu papel desagregador numa Europa em mosaico, dividida por limites e demarcações.

Para Maria Manuela Tavares Ribeiro (2003, p. 313): "A Europa da cultura é bem anterior a toda a organização política: a Europa da Cristandade, a dos mosteiros, a das universidades, a das Luzes eram bem mais unidas culturalmente do que foi, apartir do fim do século XVIII, a Europa dos Estados-nação que fragmentou e, por vezes, comprometeu essa 'consciência europeia'. E se um certo cosmopolitismo cultural se manteve através das épocas, a nível das elites, pese embora as fronteiras existentes e a necessidade de controlo das pessoas, os Estados-nação enriqueceram as consciências culturais nacionais e reduziram a parte do denominador comum, que impregna com profundidade todas as 
culturas de um continente, à herança judaico-greco-latina, quaisquer que sejam as repercussões ulteriores e muito diversas, de outras correntes".

\section{Bibliografia}

APPADURAI, A. Dimensões culturais da globalização. Lisboa: Teorema, 2004)

CANTOR, C.R. \& SMITH, C.L. . Genomics: the science and technology behind the Human Genome Project (2nd ed.). New York: John Wiley \& Sons, 1999.

CASTELLS, M. The Rise of the Network Society. Malden: Blackwell Publishers, 1997.

CAYLI, B. Social networks of the Italian mafia $\square$ the strong and weak parts. Political Science Journal, Vol. 5, No. 3, pp. 382-412, 2010

FERGUSON, N. The square and the tower. Networks, hierarchies and the struggle for global power. London: Penguin Books, 2017.

FERRÃO, J. Território, última fronteira de cidadania?. Cadernos de Geografia, número especial, 2003.

FRIEDMAN, T. L. O mundo é plano. Uma História breve do século XXI. Lisboa: Actual Editora, 2005.

GOVERNO DE PORTUGA. Conceito Estratégico de Defesa Nacional. Lisboa, 2013.

GRAY, B. Irish State Diaspora Engagement-"The Network State" and "Netizens". Éire-Ireland 47(1), 244-270, 2012.

HAESBAERT, R. A multiterritorialidade do mundo e o exemplo da $\mathrm{Al}$ Qaeda. Terra Livre, vol I, no 18, pp.37-46, 2002.

HAESBAERT, R. O mito da desterritorialização. Rio de Janeiro: Bertrand Brasil, 2004.

HARVEY, D. The condition of postmodernity. Cambridge: Blackwell, 2002.

HUNTINGTON, S: P. O Choque das Civilizações e a Mudança na Ordem Mundial. Lisboa: Gradiva, 1999.

MARSHALL, T. Prisioneiros da Geografia. Porto Salvo: Edições Saída 
de Emergência, 2017.

MASTROBUONI, G. \& PATACCHINI, E. Organized Crime Networks: an Application of Network Analysis Techniques to the American Mafia. Review of Network Economics, Vol. 11, Iss. 3, Article 10, 2012.

MONMONIER, M. How to Lie with Maps. Chicago: University of Chicago Press, 1996.

O'BRIEN, R. Global financial integration: the end of geography. London: Pinter for Royal Institute of International Affairs, 1992.

O'SUlLIVAN, F.; Why Google Rejected Berlin. https://www. citylab.com/life/2018/10/google-cancels-tech-campus-kreuzbergberlin/574378/?utm_source=facebook\&utm_medium=social\&utm content=edit-promo\&utm_term $=2018-11-02 \mathrm{~T} 14 \% 3 \mathrm{~A} 31 \% 3 \mathrm{~A} 53 \& \mathrm{utm}_{-}$ campaign=city-lab, 2018 (consultado a 4 de novembro de 2018)

RIBEIRO, M. M. T. A Europa da unidade e da diversidade culturais. Maria Manuela Tavares Ribeiro (Coord.), Europa em mutação. Cidadania. Identidades. Diversidade Cultural. Coimbra: Quarteto, 2003.

RIBEIRO, M. M. T. Introdução. Maria Manuela Tavares Ribeiro (Coord.),.Ideias de Europa: Que fronteiras?. Coimbra: Quarteto, 2004.

RIBEIRO, M. M. T. Introdução. Maria Manuela Tavares Ribeiro (Coord.), Imaginar a Europa. Coimbra: Almedina, 2010.

ROTHKOPF, D. Superclasse. A elite do poder global e o mundo que ela está a construir. Lisboa: Quidnovi, 2008.

VÁRIOS AUTORES Atlas da Europa. Lisboa: Público, 1992. 